\title{
EL DELITO DE TRATA DE SERES HUMANOS Y LA NECESIDAD DE CREACIÓN DE UNA LEY INTEGRAL ${ }^{1}$
}

\author{
Paz Lloria García ${ }^{2}$
}

Resumen: La trata de seres humanos es una de las actividades criminales más lucrativas y graves que se produce en el mundo. Buscar vías de solución alternativas a las actuales obliga a pensar en si resultaría adecuado crear una Ley integral y a qué clase de explotación debería ir referida para cumplir con las peticiones que se realizan desde Europa. Palabras clave: Trata de seres humanos; tráfico de inmigrantes; Ley integral; explotación sexual; prostitución; esclavitud.

Recibido: abril 2019. Aceptado: mayo 2019

1 Este trabajo se enmarca en el Proyecto de Investigación "La violencia sobre la mujer en el S. XXI: Género, Derecho y TIC" de la Generalitat Valenciana (AICO/2017/002-GENERALITAT VALENCIANA).

2 Profesora Titular de Derecho Penal. ORCID 0000-0003-1515-6561

Departamento de Derecho Penal. Facultad de Derecho de la Universidad de Valencia. Avda. dels Tarongers, s/n, 46022, Valencia. Email: 1loria@uv.es 


\begin{abstract}
Trafficking in human beings is one of the most lucrative and serious criminal activities in the world. Finding ways to solve alternatives to current ones requires thinking about whether it would be appropriate to create an integral Law and to what kind of exploitation should be referred to comply with the requests made from Europe.
\end{abstract}

Keywords: Trafficking in human beings; smuggling of migrants; Integral law; sexual exploitation; prostitution; slavery.

\title{
1. Introducción: Situación actual y razones para un cambio
}

Bien adentrado el s. XXI la trata de seres humanos se presenta como uno de los crímenes más graves que se producen en nuestra sociedad por diferentes razones.

En primer lugar, y sin ánimo de exhaustividad, la compra y venta de seres humanos afecta a múltiples bienes jurídicos fundamentales: la vida, la salud, la integridad física o psíquica, la libertad, la libertad sexual, la integridad moral, siendo que siempre se ve afectada la dignidad, como elemento quasi definidor del hecho de la trata. Estos bienes jurídicos se ven lesionados o puestos en peligro (conjunta o independientemente) sin importar la finalidad de explotación que acompaña a la trata; afección a la que se suma la que se derive del concreto acto de explotación (sexual, labora, delictual, etc.) que finalmente se produzca si la persona no es liberada durante el proceso que culminará con su esclavitud.

En segundo lugar, el delito implica una situación global que afecta a un numerosísimo grupo de personas en todo el mun$\mathrm{do}^{3}$ aunque los datos exactos sean difíciles de concretar, atendiendo, fundamentalmente a la gran cifra negra que existe en

3 Vid., el informe de 2016 realizado por UNDOC https://www.unodc.org/documents/lpo-brazil//Topics_TIP/Publicacoes/2016_Global_Report_on_Trafficking in Persons.pdf 
este delito 4 . Lo cierto es que el último informe habla de que en 2016 se produjo un incremento de víctimas tan importante que dio lugar a las cuantías más elevadas de los últimos 13 años (un $40 \%$ aproximadamente). La explicación puede encontrarse en que, efectivamente, ha aumentado el número de víctimas pero, también, se puede pensar en una mayor efectividad en la identificación de las mismas. En todo caso, y aunque la trata afecta tanto a hombres como a mujeres, no podemos decir que sea un fenómeno objetivamente neutro desde el punto de vista del género, tal y como se apunta en el Plan Integral de lucha contra la trata de mujeres y niñas con fines de explotación sexual (20152018) del Ministerio de Sanidad, Servicios Sociales e Igualdad 5 , donde habría que incluir también otros tipos de explotación femenina quizá aún no detectados (para llevar a cabo actos de gestación por sustitución por ejemplo), aunque es cierto que, tal y como ha puesto de manifiesto VILLACAMPA ESTIARTE, los datos van "equilibrándose" con los que se constatan en otros tipos de trata ${ }^{6}$.

A este respecto, la (OIT) estima en su informe "Trabajo forzoso, tráfico humano y esclavitud" del año 2014, que el número total personas entre las que están incluidas las víctimas de la explotación sexual asciende a cerca de 21 millones de personas. Los datos actualizados se encuentran en el informe de 2018.

4 Muestra datos sobre esta cuestión Serra Cristóbal, R.: "La trata de mujeres como una de las formas más atroces de violencia contra la mujer", en Martín Sánchez, M. (Dir.).: Estudio integral de la violencia de género, Valencia, 2018, pp. 272 y 273. También, Villacampa Estiarte, C. y Torres Rosell, N.: "Trata de seres humanos para explotación criminal: ausencia de identificación de las víctimas y sus efectos", en EPC, Vol. XXXVI (2016), p. 773.

5 Consultado el 3 de diciembre de 2018. Disponible en

http://www.violenciagenero.igualdad.mpr.gob.es/planActuacion/planContraExplotacionSexual/docs/Plan_Integral Trata_18_Septiembre2015 2018.pdf.

Conclusión que también se alcanza en el Informe de las Naciones Unidas Global report on trafficking in persons, 2018, UNDOC, disponible en XXXX.

6 Villacampa Estiarte, C. y Torres Rosell, N.: "Trata de seres humanos...", cit., p. 773. 
En tercer lugar, la relación con la globalización revela una de las causas del crecimiento del mismo: la transnacionalidad de la conducta unida a la utilización de las tecnologías de la información y la comunicación en su comisión, dificulta enormemente su persecución, siendo además que el delito se configura, desde el punto de vista de su naturaleza jurídica, como un delito iterativo que se prolonga en el tiempo y en el espacio. Teniendo en cuenta además, que las acciones de trata están íntimamente relacionadas con la criminalidad organizada, los Estados se ven obligados a adoptar soluciones normativas comunes, con la finalidad de dotar de unidad al castigo y facilitar la lucha contra los autores del crimen.

En este sentido, hasta hace bien poco, la mayoría de los mandatos supranacionales ponían el foco de atención en la punición del proceso de traslado, dejando en segundo plano a las personas que soportan el delito. Se adoptaba así una visión criminocéntrica que hacía que las víctimas sufrieran, junto a su situación de vulnerabilidad una doble victimización pues, algunas de sus circunstancias, como la diferencia de idioma, cultura o religión, conducía, en no pocas ocasiones, a no identificar correctamente a las víctimas de trata y confundirlas con inmigrantes ilegales que se desplazan voluntariamente. En este entendimiento el objetivo principal es el delito, y su castigo aparece como la máxima preventiva. Esta posición se corresponde con las primeras consideraciones de la trata desde el punto de vista normativo y da un giro a partir de la aprobación del Protocolo de Palermo. Desde este momento, y como solución alternativa a estas cifras tan elevadas de personas sometidas a la trata, la doctrina solicita que la cuestión se aborde desde un prisma que atienda a las necesidades de la víctima (sin descuidar la vertiente punitiva) a través de la denominada "política de las 3P" (prevención, persecución, protección) y que tome como referencia la perspectiva de los derechos fundamentales de las víctimas?

7 Vid., entre otras, Villacampa Estiarte, C.: "El delito de trata de seres humanos" en Gonzalo Quintero (Dir.): Comentario a la Reforma penal de 
Con este cambio se impone, pues, establecer criterios que permitan proporcionar protección global, para evitar, entre otras situaciones, los procesos de revictimización o de exclusión de la protección directamente.

Este es, además, el mandato que contiene la Directiva 2011/36/UE de 5 abril de $2011^{8}$, que recoge lo que ha se venido a llamar, una orientación victimocéntrica, cuando establece la visión integrada y global como requisito para alcanzar una lucha más eficaz frente a esta realidad criminal.

Y aquí se encuentra el primer motivo para la creación de una ley integral. Las leyes integrales se nos presentan casi como una nueva técnica de codificación que responden a las necesidades de transversalidad que reclaman algunas situaciones como la que estamos exponiendo. La idea es que esta regulación ha de favorecer un tratamiento normativo conjunto, que proporcione una visión global del problema a fin de poder coordinar adecuadamente la protección de las víctimas tomando en cuenta una valoración real de sus necesidades y que facilite la toma de decisiones unitarias, que es lo que, en definitiva, reclama la Directiva9.

En este marco, el informe GRETA para la Implementación de España del Convenio del Consejo de Europa pone de manifiesto cómo, a pesar de haberse progresado en la lucha contra la trata, nuestro país se ha centrado básicamente en la trata con fines de explotación sexual, reprochando la menor atención prestada a otros tipos de explotación y requiriendo a nuestro país para que inicie una política de tutela integral que proporcione una protección más eficaz frente al fenómeno que se analiza ${ }^{10}$.

2015, Pamplona, 2015, pp. 399 a 402 y Serra Cristóbal, R.: "La trata de mujeres...", cit., pp. 276 y 277.

8 Disponible en https://www.boe.es/doue/2011/101/L00001-00011.pdf

9 Vid., infra, epígrafe 8.

10 Report concerning the implementation of the Council of Europe Convention on Action against Trafficking in Human Beings by Spain, disponible en https://rm.coe.int/greta-2018-7-frg-esp-en/16808b51e0 (fecha de consulta 3 de diciembre de 2018). 
Con este punto de partida, no parece que sea muy adecuado pensar en un Ley integral en la que solo las víctimas de explotación sexual encuentren cobijo, aunque existen otras razones que avalan esta idea y que se expondrán posteriormente.

A mi modo de ver, para valorar cuál es el mejor método para llevar a cabo esa tutela global que se nos exige, y que también es demandada por un importante número de actores civiles vinculados a la lucha contra la trata ${ }^{11}$, creo conveniente realizar un análisis de los aspectos técnicos que tienen que ver con la vertiente punitiva y una exposición de las necesidades de protección desde la perspectiva victimológica y de derechos humanos.

\section{Cuestiones previas: la necesaria distinción entre trata de seres humanos y otras realidades}

\subsection{Trata y tráfico: dos realidades distintas, dos regu- laciones diferentes}

A pesar que desde un punto de vista puramente práctico resulte difícil detectar a las víctimas de trata cuando estas llegan en una patera, en un camión o por cualquier otro medio mezcladas con inmigrantes que voluntariamente acceden al país sin los correspondientes permisos administrativos, es una constante en los planes y protocolos distinguir entre ambos fenómenos, pues necesariamente se corresponden con dos realidades que merecen tratamientos diferenciados ${ }^{12}$.

Ciertamente, la confusión es una constante histórica, que deriva de la identificación entre trata con fines de explotación sexual y prostitución y del proceso de victimización institucio-

11 Desde el mes de julio de 2018 son muchas las noticias de prensa en este sentido; se pueden ver, entre otras, la publicada por el Diario Sur https://www. diariosur.es/sociedad/reclaman-integral-trata-20180730213539-ntrc.html a propósito de la subcomisión preparatoria del Pacto de Estado.

12 Otra cosa será que resulte necesario instruir a las profesionales que reciben a las víctimas de uno u otro delito para que sepan discernir cuando el transporte ha sido consentido y cuando no, incluyendo los supuestos de consentimiento viciado, lo que desde luego no resulta nada sencillo. 
nal de todos los migrantes irregulares, en un proceso de vaivén normativo que nos lleva de nuevo a la confusión, como muy bien ha explicado MAQUEDA ABREU ${ }^{13}$.

Sin embargo, es importante diferenciar ambas situaciones, si se desea realizar una correcta tutela de los intereses de las personas que han llegado a nuestro país por un procedimiento o por otro. El momento de detección e identificación de la víctima como tal, es uno de los más importantes, pues es cuando más vulnerable se puede sentir la víctima de trata y cuando más difícil puede ser su colaboración si, en lugar de recibir el trato de perjudicada, se la identifica como inmigrante ilegal y su "liberación" la convierte en sujeto pasivo de una sanción administrativa o penal ${ }^{14}$.

En este sentido, el Plan integral de lucha contra la trata de mujeres y niñas con fines de explotación sexual (2015-2018) ${ }^{15}$, intenta marcar la frontera entre trata de seres humanos y tráfico de inmigrantes y establece determinados objetivos de formación específica para identificar a unas y otras víctimas y poder proporcionar los recursos adecuados en cada caso ${ }^{16}$.

Dada la importancia de la cuestión, conviene aclarar previamente, de qué hablamos cuando hablamos de trata.

La trata se califica como una forma de esclavitud (en contra, no sin razón, MAQUEDA ABREU ${ }^{17}$, como explicaré des-

13 Vid., una explicación de este proceso en Maqueda Abreu, M.L.: “A propósito de la trata y de las razones que llevan a confundir a 1@s inmigrantes con esclav@s", en Carbonell Mateu, J.C., González Cussac, J.L. y Orts Berenguer, E., (Dir.) y Cuerda Arnau, M.L. (Coord.): Constitución, Derechos fundamentales y sistema penal (semblanzas y estudios con motivo del setenta aniversario del profesor Tomás Salvador Vives Antón), Tomo II, Valencia, 2009, passim.

14 Vid., Serra Cristóbal, R.: "La trata de mujeres...", cit., pp. 279.

15 Plan Del Ministerio de Sanidad, Servicios Sociales e Igualdad, disponible en http:/www.violenciagenero.igualdad.mpr.gob.es/planActuacion/planContraExplotacionSexual/docs/Plan_Integral_Trata_18_Septiembre2015_2018.pdf

16 Vid., Plan..., cit., pp. 62 a 64.

17 Maqueda Abreu, M.L.: “A propósito de la trata y de las razones...", cit., pp. 1245 y ss. 
pués), en la medida en que el traslado de personas de un lugar a otro se lleva a cabo doblegando la voluntad de las víctimas, bien porque su consentimiento está viciado mediante el engaño, bien porque resulta inexistente al ser su traslado forzoso (por el uso de la violencia, la intimidación o el abuso de cualquier situación de debilidad de la víctima o de posición de dominio del sujeto activo). Junto a ello, la trata tiene como finalidad la explotación de la persona en cualquiera de sus vertientes, o para someterla a trabajos forzados, extracción de órganos, mendicidad o cualquier otra forma de esclavitud. Es decir, se produce, por el mero hecho de la trata, una explotación de derechos humanos tal y como ha afirmado SERRA CRISTÓBAL ${ }^{18}$.

La trata viene a coincidir con el fenómeno denominado internacionalmente como trafficking of human beings, diferenciándose del smuggling of migrants o tráfico ilícito de inmigrantes en que, en este último caso, la acción consiste en un movimiento organizado de personas de un país a otro, con ánimo de lucro, en el que pueden concurrir -normalmente es así- situaciones de abuso, pero no engaño o coacción o violencia, rompiéndose la relación entre traficante e inmigrante una vez alcanzado el propósito, que no es otro que el de hacer llegar a la persona al lugar de destino donde el extranjero espera encontrar una mejor vida ${ }^{19}$.

En este sentido, y diferenciados los dos fenómenos, la trata supone uno de los mercados negros que mayores ingresos generan para la criminalidad organizada junto con el tráfico de armas y de drogas. Su cercanía a la esclavitud radica en la afectación de la dignidad del ser humano, convirtiéndolo en objeto de intercambio económico y trasladándolo de un lugar a otro en función de las necesidades productivas ${ }^{20}$, pero como ya he adelantado, no puede identificarse la acción de captación y traslado

18 Serra Cristóbal, R. en Serra Cristóbal, R. y Lloria García, P.: La trata sexual de mujeres. De la represión del delito a la tutela de la víctima, Madrid, 2007, pp. 19 a 21.

19 Vid., Serra Cristóbal, R.: "La trata de mujeres como...", cit., pp. 274 y 275.

20 García Arán, M.: “Introducción”, en García Arán, M (Coord.), Trata de personas y explotación sexual, Granada, 2006, pp. 5 a 31. Más recientemente, 
con la situación de esclavitud que, realmente, se produce en un momento posterior, en el momento de la explotación ${ }^{21}$.

Precisamente por ello, no resulta extraño el abundante número de resoluciones y normativa de carácter internacional y comunitario que sobre su persecución y castigo se ha dictado en los últimos años. Entre otras, y sin ánimo de exhaustividad, se pueden mencionar La Declaración de Derechos del Hombre de 1948, el Convenio de Naciones Unidas para la represión de la trata de personas y de la explotación de la prostitución ajena de 1949, la Convención de Ginebra de 1956, la Convención sobre los derechos de niño de 1989, el Convenio del Consejo de Europa sobre la lucha contra la trata de seres humanos hecho en Varsovia en 2005, etc. ${ }^{22}$.

En todos ellos se alude a la prohibición y necesidad de reprimir las situaciones de trata. En este marco, y ya en el ámbito europeo, se han dictado una serie de Decisiones instando a los Estados a dictar normas de tutela penal dentro de unos marcos y con ciertos requisitos, siendo la más representativa, por ser la que dio lugar a la regulación específica en el art. 177 bis, la Decisión marco del Consejo 2002/629/JAI, de 19 de julio, relativa a la lucha contra la trata de seres humanos ${ }^{23}$, sustituida por la Directiva 2011/36/EU de 5 de abril de 2011 relativa a la prevención

Pérez Ferrer, F.: "Sobre el delito de trata de seres humanos en el Código penal español tras la LO 1/2015, de 30 de marzo", en Estudios jurídicos penales y criminológicos en homenaje al Prof. Dr. Dr. H.C. múlt. Lorenzo Morillas Cueva, Dykinson, 2018, p. 1471.

21 Vid., Maqueda Abreu, M.L.: “Trata y esclavitud no son lo mismo, pero ¿qué son?" en Estudios jurídicos penales y criminológicos en homenaje al Prof. Dr. Dr. H.C. mult. Lorenzo Morillas Cueva, Dykinson, 2018, pp. 1251 y ss.

22 Sobre las diferentes normas europeas y su influencia en la evolución legislativa penal se puede ver Lloria García, P. en Serra Cristóbal, R. y Lloria García, P.: La trata sexual..., cit., pp. 157 a 170.

23 Disponible en https://www.boe.es/doue/2002/203/L00001-00004.pdf. Esta Decisión Marco supuso la derogación de la Acción Común de 1997 en lo relativo a la trata de seres humanos, por lo que con este instrumento se renueva el compromiso de los Estados miembros de la unión para adoptar medidas comunes contra la trata con fines de explotación laboral y sexual (vid., Lloria García, P. en Serra Cristóbal, R. y Lloria García, P.: La trata sexual de mujeres..., cit., pp. 161 y ss.). 
y lucha contra la trata de seres humanos, ya citada anteriormente. Norma que, como advierte el Preámbulo de la LO 1/2015, es la que ha provocado la modificación de la regulación penal del delito de trata de seres humanos.

Hay que recordar, por tanto, que hasta el año 2010 en nuestro ordenamiento punitivo la regulación penal sobre la materia resultaba dispersa y técnicamente discutible. El art. 318 bis dedicado a la tutela de los derechos de los ciudadanos extranjeros, castigaba en su primer número las conductas de inmigración ilegal (smuggling) mientras que en el apartado segundo se recogía como tipo agravado la figura de trata con fines de explotación sexual (trafficking). Por su parte, el art. 313.1 se ocupaba de los supuestos de inmigración clandestina con finalidad de explotación laboral ${ }^{24}$.

La interpretación de ambas figuras traía consigo dificultades a la hora de deslindar ciertos tipos de conductas como la prostitución forzada y la trata ${ }^{25}$ y generaba no pocos problemas concursales, a la par que obligaba a reducir el castigo para el caso de sujetos pasivos extranjeros, dejando de lado la protección de los nacionales sin olvidar las dudas que se suscitaban en torno a la determinación del bien jurídico protegido, precisamente por la confusión entre las situaciones de trata y las de tráfico de inmigrantes ${ }^{26}$.

Con la introducción del art. 177 bis, y la derogación de la previsión del núm. 2 del art. 318 bis y del núm. 1 del art. 311 parece que el legislador atendió a las críticas emitidas tradicionalmente por la doctrina respecto de la tipificación contenida en el art. 318 bis, que confundía supuestos de tráfico ilegal de inmigrantes con casos de trata de personas.

24 Vid., Lloria García, P. en Serra Cristóbal, R. y Lloria García, P.: La trata sexual de mujeres..., cit., pp. 195 y ss.

25 Confusión que a fuerza de producirse se mantiene, como explica Maqueda Abreu ("A propósito de la trata...", cit., pp. 1245 a 1255); vid., también, también, Serra Cristóbal, R.: "La trata de mujeres como...", cit., pp. 275.

26 Serra Cristóbal, R. en Serra Cristóbal, R. y Lloria García, P.: La trata sexual de mujeres ..., cit., pp. 178 y ss. 
Esta razón ya por si sola hubiera autorizado la modificación de la regulación existente hasta el momento. Pero, además, hay que tomar en consideración que en los últimos tiempos se ha producido un incremento cuantitativo de estas conductas, que siguen aumentando ayudadas por las nuevas tecnologías que facilitan la comisión de los delitos subsiguientes a la trata -explotación sexual, tráfico de órganos, explotación laboral-. Argumentos que siguen siendo válidos y que se añadían al mandato contenido en la Decisión Marco 2002/629 mencionada anteriormente y lo dispuesto en el Protocolo para prevenir, reprimir y sancionar la trata de personas, especialmente de mujeres y niños, del Anexo II de la Convención de la ONU contra la delincuencia organizada transnacional, de 11 de noviembre de 2000 (NY) -Protocolo de Palermo II-, lo que justificaba sobradamente la inclusión de la figura en el texto punitivo.

Posteriormente, la Directiva de 2011 hizo necesaria una nueva modificación del texto penal, tal y como se advierte el Preámbulo de la LO 1/2015. Según el mismo, a pesar que la redacción penal que se propuso en 2010 acoge el proyecto que finalmente dio lugar a la Directiva de 2011, era necesario reformar el art. 177 bis en sus apartados 1 y 4, con la finalidad de reflejar completamente los mandatos de la norma europea, incluyendo la conducta de entrega o recepción de pago para obtener "el consentimiento de la persona que controla a las víctimas, o la trata con la finalidad de concertar matrimonios forzados. También se tipifica la explotación con la finalidad de que las víctimas cometan actos delictivos para los explotadores". Igualmente, la modificación incluye la delimitación del concepto de vulnerabilidad y se agrava la pena para los casos de creación de peligro de causación de lesiones graves, con las consecuencias que expondré al analizar el delito.

De este modo se consolida el diferente tratamiento penal -al menos formalmente- de dos realidades (trata, art. 177 bis y tráfico, art. 318 bis) que, aunque convergentes, afectan a bienes jurídicos diferentes y deben ser claramente diferenciadas, sobre 
todo si atendemos a la necesidad de proporcionar un tratamiento victimológico adecuado a las personas sometidas a trata, lo que requerirá de actuaciones normativas de futuro ${ }^{27}$.

Y esta, podría ser la segunda razón que justificara la creación de una ley integral de trata. Por un lado, debería intentar evitar la dispersión normativa penal y la asistematicidad y por otro, clarificar la diferencia entre trata e inmigración ${ }^{28}$.

\subsection{Trata para explotación sexual y prostitución: dos situaciones paralelas que no hay que confundir.}

Del mismo modo que se produce confusión entre el fenómeno del tráfico ilegal de migrantes con la trata de seres humanos, en el momento actual se tiende a identificar la trata con fines de explotación sexual con la prostitución, con lo que no puedo estar de acuerdo.

Tal y como afirma SERRA CRISTOBAL ${ }^{29}$ la prostitución voluntaria debe quedar excluida de la trata. Ni todas las mujeres que ejercen la prostitución lo hacen en condiciones de explotación (aunque haya un gran número que sí) ni todas proceden de la trata.

Creo que asiste la razón a MAQUEDA ABREU cuando, afirma que esta identificación entre los dos fenómenos tiene más que ver con una estrategia política de fomento de campañas de seguridad de fronteras y de sustento al abolicionismo, desde una alianza curiosa entre capitalismo y moralidad adoptada por algún sector del feminismo, que con la realidad de la prostitución en nuestros días ${ }^{30}$.

27 En este sentido se ha pronunciado también la jurisprudencia. Entre otras, se pueden citar las SSTS 910/2013, de 3 de diciembre; 298/2015, de 13 de mayo; 185/2016, de 4 de marzo y 2014/2017, de 29 de marzo.

28 Aunque la diferencia resulta muy compleja como demuestran los hechos narrados en la STSJ Oviedo 12/2019, de 4 de marzo.

29 Serra Cristóbal, R. en Serra Cristóbal, R. y Lloria García, P.: La trata sexual de mujeres..., cit., p. 20)

30 Maqueda Abreu, M.L.: "Trata y esclavitud no son...", cit., passim; Vid., también, de la misma autora "Demasiados artificios en el discurso jurídico 
Precisamente por ello resulta, al igual que ocurría en el epígrafe anterior, absolutamente necesario distinguir entre una situación y otra.

En el fenómeno de la prostitución poco hemos avanzado, puesto que el foco de la misma sigue siendo la mujer ${ }^{31}$, olvidando al "intermediario" que obliga a la mujer a prostituirse y al cliente que busca sus servicios ${ }^{32}$. Y el cambio debe venir por aquí.

El ejercicio coactivo de la actividad ciertamente se produce, en mayor medida, sobre mujeres extranjeras por su especial situación de vulnerabilidad. Pero ello no significa que el principal problema radique en la determinación a la prostitución ${ }^{33}$. Lo determinante para el delito de trata es que se produzca una situación de explotación; esto es, que la mujer que se prostituye esté sometida a condiciones de esclavitud.

$\mathrm{Y}$ esto es fundamental, porque cuando se habla de trata con fines de explotación sexual se olvida que hay un importante grupo de mujeres explotadas sexualmente, no nacionales, y que proceden del tráfico ilegal de personas, no de la trata. Y ello no significa que no estén sometidas a situaciones de explotación.

Por otro lado, sigue existiendo un número de mujeres que ejercen la prostitución de forma voluntaria y a las que, las propias instituciones han rechazado sus peticiones dirigidas a que se regule su situación ${ }^{34}$.

sobre la trata de seres humanos" en Liber Amicorum en homenaje del Profesor Juan Terradillos Basoco, Valencia, Tirant lo Blanch, 2018, pp. 1197 y ss. También, García Arán, M.: "Introducción...", cit., pp. 28 a 31.

31 Aunque también existe la prostitución masculina y no solo la homosexual.

32 Cuenca García, M.J.: "El perfil criminológico del tráfico para explotación sexual en España: un fenómeno viejo con características nuevas", en García Aran, M (Coord.): Trata de personas ..., cit., pp. 109 y ss.

33 Muchas de ellas ya la ejercían en sus países de origen (Cuenca García, M.J.: "El perfil criminológico..., cit., p. 153).

34 Recuérdese el caso del intento de inscripción del sindicato de prostitutas que se ha producido en septiembre de 2018, y que ha generado una gran polémica mediática. 
Todo ello debe llevar a una reflexión sosegada sobre algunas cuestiones.

En primer lugar, si es adecuado continuar con la línea abolicionista clásica que se ha instalado en el discurso políticamente correcto puesto que ello implica, en el fondo, seguir cargando las tintas en la posición de la mujer que va a continuar en la ilegalidad por su condición de prostituta y por su condición, mayoritariamente, de extranjera ${ }^{35}$.

En segundo lugar, creo que hay que aclarar que, dado que se ha producido un cambio en el ámbito de la prostitución, con un importante número de mujeres extranjeras en su ejercicio, resulta imprescindible diferenciar aquellas que proceden de la trata de las que proceden del tráfico ilegal, teniendo en cuenta que si se encuentran en situación de explotación porque su consentimiento resulta invalido, dada su situación de extrema vulnerabilidad, deben recibir un trato que evite su revictimización desde el mismo momento en que se produce la persecución policial del explotador ${ }^{36}$, lo que de nuevo nos conduce, no ya a la necesidad de diferenciar tráfico y trata, sino también a diferenciar entre trata y explotación. Es decir, entre trata y esclavitud.

Por último, no hay que dejar de lado, dentro de la necesidad de cambiar el objetivo y dejar de ponerlo sobre la mujer, la necesidad de regular adecuadamente el delito de explotación para así poder perseguir al intermediario o explotador de una manera adecuada o proporcional.

35 Esta es una de las razones que avala el abolicionismo: la dificultad de reconocer derechos a las extranjeras ilegales. Una explicación muy sencilla y clarificadora entre abolicionismo y prohibicionismo en relación con las políticas sobre la prostitución y la inmigración se puede ver en García Arán, M.: "Introducción...", cit., pp. 28 a 31.

36 Recuérdese el asunto G.J. contra España, dilucidado por el TEDH (2016) donde una mujer extranjera denuncio el trato recibido por agentes de policía españoles que la detuvieron, esposaron, etc., desatendiendo los derechos que como víctima tenía reconocidos en el art. 25 del estatuto de la víctima y con descuido de las mínimas normas de atención a las víctimas en estos casos. 
Una mera revisión de las penas del delito de trata y del de prostitución coercitiva pone de manifiesto la desproporción. El máximo de pena prevista en el art. 187.1 es de cinco años de prisión, lo que viene a coincidir con el mínimo de la trata, lo que hace dudar de la correcta proporcionalidad entre penas, tomando en consideración la mayor gravedad del delito de explotación.

Todo ello también ha de conducirnos a la reflexión, de nuevo de la mano de MAQUEDA ABREU, sobre si la trata y la esclavitud es lo mismo y qué necesidades punitivas restan por cubrir en este ámbito.

\subsection{Trata y esclavitud: la última confusión.}

Como se acaba de explicar, el hecho del traslado puede ser diferente y, por tanto, habrá que diferenciar los casos de traslado voluntario de los de trata. Pero, una vez que se ha llegado al lugar de destino, es importantísimo también diferenciar el proceso del traslado del hecho de la explotación, sobre todo en relación con la prostitución donde no se debe olvidar que nos encontramos con diferentes realidades: la que se ejerce libremente (generalmente por nacionales), y la que se ejerce coactivamente, donde encontraremos explotadas nacionales, pero mayoritariamente extranjeras, que pueden haber llegado al país a través de situaciones de trata o de tráfico, lo que no impide, en todo caso, su consideración como víctimas de explotación aunque su llegada al país se haya producido por cauces diferentes ${ }^{37}$.

Este panorama nos lleva al escenario de la identificación de la trata con la esclavitud, equivalencia que ya he adelantado no resulta aceptable, pues la esclavitud va más allá de la trata y más allá de la explotación sexual para la prostitución.

El trabajo de MAQUEDA ABREU sobre la diferencia entre trata y esclavitud ya citado, es el que sirve de guía a este epígrafe.

37 Incluso pueden haber llegado de manera legal, lo que en principio las asimilaría formalmente a las nacionales, aunque materialmente su vulnerabilidad será generalmente mayor. 
Como muy bien dice la autora mencionada, y en un breve resumen, podemos afirmar que la trata es el hecho que inicia la esclavitud que no se produce hasta que llega el momento de la explotación.

La trata se configura en nuestro ordenamiento jurídico como un instrumento para la explotación y por eso, aunque la trata entiendo que se ha de considerar un delito con sustantividad propia y que existe una estrecha relación entre trata y explotación, no es menos cierto, como afirma MAQUEDA ABREU ${ }^{38}$ que existe una grave incongruencia entre las penas que corresponden a la $\operatorname{trata}^{39}$ y los delitos de explotación misma, y que no pueden hacerse equivalentes.

Si se analizan los fines de la explotación que se exigen para que se de por consumada la trata, podremos observar cómo lo que se castiga es el riesgo de explotación con lesiones de bienes jurídicos que derivan del propio proceso, pero no siempre se contempla la sanción, o no siempre la más adecuada, para la explotación.

Así, por ejemplo, ya he expuesto como el marco de la trata va de cinco a ocho años de prisión, lo que no resulta proporcional a la pena de prostitución coercitiva no asociada a la trata, que prevé en el art. 187.1 (una sanción de dos a cinco años de prisión), o la explotación laboral, regulada en el art. 311, con una pena de seis meses a seis años de prisión o, por poner otro ejemplo más, el matrimonio forzoso que castiga el art. 172 bis con una prisión de seis meses a tres años y seis meses. Y que decir tiene, cuando atendemos a los fines de explotación para la mendicidad, que solo se castiga en el art. 322 para el caso de menores, o para la explotación delictiva que no se contempla expresamente como delito ${ }^{40}$.

38 Maqueda Abreu, M.L.: “Trata y esclavitud no son lo mismo...”, pp. 1251 y ss.

39 Que vendría a configurarse como los actos preparatorios de la explotación. En este sentido, por ejemplo, SAP de Valladolid 80/2015, de 27 de marzo de 2015.

40 Maqueda Abreu, M.L.: “Trata y esclavitud no son lo mismo...," cit., p. 1255. 
Ciertamente se pueden establecer concursos entre la trata y la explotación, pero como también avisa MAQUEDAABREU, esta solución nos lleva a correr el riesgo de romper con la idea de proceso, de itinerancia que acompaña al delito de trata ${ }^{41}$.

Además, en los casos en los que la explotación no se castiga no es posible el concurso.

Es el supuesto relatado en la STS de 3 de marzo de 2016, donde se obliga a los sujetos tratados a robar cobre y naranjas ${ }^{42}$. En estos casos solo se va a castigar por los delitos de trata, salvo que se acuse, por ejemplo, de coacciones o tratos inhumanos o lesiones. Pero, en todo caso, son delitos instrumentales que no contemplan la situación de esclavitud.

Junto a ello no hay que olvidar, como después se explica, la dificultad que entraña la elección de uns istema de numeros clausus en relación con los fines de explotación. Esta técnica no resulta la mas aconsejable pues olvida supuestos de explotación que no incorpora por no estar contemplados en la normativa europea.

Así, por ejemplo, no incluye la trata para adopción ilegal, o el uso de menores en conflictos armados o para la realización de experimentos clínicos o farmacológicos ${ }^{43}$.

Si se observa, cuando llega el momento de la explotación, la víctima vuelve a estar olvidada. Quizá por ello se demanda

\section{Ibidem}

42 De manera similar ocurre con la situación de explotación para la mendicidad descrita en la SSAP Cádiz 206/2013, de 28 de junio de 2013, SAP $536 / 2015$, de Sevilla de 20 de octubre de 2015 o la SAP de Baleares 359/17, de 1 de septiembre. En esta última se condena por un delito de trata y otro de lesiones leves, a una pena de 10 años de prisión. También la SAP de la Coruña 244/2018, de 26 de junio. En el caso de explotación laboral, la SAP de la Coruña, de 29 de julio de 2017, establece penas muy elevadas en un caso de trata para explotación laboral de dos varones españoles esclavizados en España para trabajar como feriantes, abusando de una situación especial vulnerabilidad por problemas de salud físicos y psíquicos.

43 Ver con detalle, Maqueda Abreu, M.L.: "Trata y esclavitud no son lo mismo...", cit., pp. 1255 a 1260. 
por parte de la doctrina la creación de un delito de esclavitud que contemple el total desvalor del sometimiento de una persona al poder de otros, con independencia del delito de trata.

Este delito recogería el "plus de deshumanización" que padecen las víctimas de trata, y permitiría configurar la trata como un delito de peligro respecto del de explotación subsiguiente $^{44}$.

Esta solución propuesta por MAQUEDA ABREU y a la que me sumo, no estaría exenta de dificultades como la propia autora expone ${ }^{45}$ y que podrían ser superadas si se siguen determinadas pautas.

En todo caso, la autora propone crear un nuevo delito de esclavitud que describa "el estado de despersonalización que se produce cuando alguien está bajo el control de otros que usan y disponen y buscan provecho de su persona como hacían los antiguos dueños esclavistas" ${ }^{46}$, con lo que no puedo estar más de acuerdo. Primero, para solventar vacíos legales y segundo, para garantizar la proporcionalidad que no se consigue con la mala técnica de incorporación, sin más, al ordenamiento interno de las normas europeas.

Aun así, y para alcanzar una conclusión definitiva, entiendo convenientemente analizar el delito de trata de seres humanos en su redacción vigente.

\section{Análisis del delito de trata de seres humanos}

Como he dicho más arriba, la reforma operada en el Código penal por la LO 1/2015 ha modificado la regulación penal de la trata y ha introducido otros preceptos que habrá que relacionar con esta nueva tipificación, como el de matrimonio forzo-

44 Maqueda Abreu, M.L.: "Trata y esclavitud no son lo mismo...”, cit., p. 1260.

45 Maqueda Abreu, M.L.: "Trata y esclavitud no son lo mismo...”, cit., pp. 1261 a 1263.

46 Maqueda Abreu, M.L.: “Trata y esclavitud no son lo mismo...”, cit., p. 1263. 


\section{sos recogido en el art. 172 bis. Tras la reforma, el art. 177 bis $^{47}$ se presenta con una estructura compleja, recogiéndose junto al tipo}

47 Dice así:

«1. Será castigado con la pena de cinco a ocho años de prisión como reo de trata de seres humanos el que, sea en territorio español, sea desde España, en tránsito o con destino a ella, empleando violencia, intimidación o engaño, o abusando de una situación de superioridad o de necesidad o de vulnerabilidad de la víctima nacional o extranjera, o mediante la entrega o recepción de pagos o beneficios para lograr el consentimiento de la persona que poseyera el control sobre la víctima, la captare, transportare, trasladare, acogiere o recibiere, incluido el intercambio o transferencia de control sobre esas personas, con cualquiera de las finalidades siguientes:

a) La imposición de trabajo o de servicios forzados, la esclavitud o prácticas similares a la esclavitud, a la servidumbre o a la mendicidad.

b) La explotación sexual, incluida la pornografía.

c) La explotación para realizar actividades delictivas.

d)La extracción de sus órganos corporales.

e) La celebración de matrimonios forzados.

Existe una situación de necesidad o vulnerabilidad cuando la persona en cuestión no tiene otra alternativa, real o aceptable, que someterse al abuso.

2. Aun cuando no se recurra a ninguno de los medios enunciados en el apartado anterior, se considerará trata de seres humanos cualquiera de las acciones indicadas en el apartado anterior cuando se llevare a cabo respecto de menores de edad con fines de explotación.

3. El consentimiento de una víctima de trata de seres humanos será irrelevante cuando se haya recurrido a alguno de los medios indicados en el apartado primero de este artículo.

4. Se impondrá la pena superior en grado a la prevista en el apartado primero de este artículo cuando:

a) se hubiera puesto en peligro la vida o la integridad física o psíquica de las personas objeto del delito;

b) la víctima sea especialmente vulnerable por razón de enfermedad, estado gestacional, discapacidad o situación personal o sea menor de edad.

Si concurriere más de una circunstancia se impondrá la pena en su mitad superior.

5. Se impondrá la pena superior en grado a la prevista en el apartado 1 de este artículo e inhabilitación absoluta de seis a doce años a los que realicen los hechos prevaliéndose de su condición de autoridad, agente de esta o funcionario público. Si concurriere además alguna de las circunstancias previstas en el apartado 4 de este artículo se impondrán las penas en su mitad superior. 
básico, varios tipos agravados o hiper-agravados, en atención a criterios tales como la situación personal del sujeto pasivo o la pertenencia de los sujetos activos a grupos organizados. Igualmente se contiene el castigo de los actos preparatorios punibles,

6. Se impondrá la pena superior en grado a la prevista en el apartado 1 de este artículo e inhabilitación especial para profesión, oficio, industria o comercio por el tiempo de la condena, cuando el culpable perteneciera a una organización o asociación de más de dos personas, incluso de carácter transitorio, que se dedicase a la realización de tales actividades. Si concurriere alguna de las circunstancias previstas en el apartado 4 de este artículo se impondrán las penas en la mitad superior. Si concurriere la circunstancia prevista en el apartado 5 de este artículo se impondrán las penas señaladas en este en su mitad superior.

Cuando se trate de los jefes, administradores o encargados de dichas organizaciones o asociaciones, se les aplicará la pena en su mitad superior, que podrá elevarse a la inmediatamente superior en grado. En todo caso se elevará la pena a la inmediatamente superior en grado si concurriera alguna de las circunstancias previstas en el apartado 4 o la circunstancia prevista en el apartado 5 de este artículo.

7. Cuando de acuerdo con lo establecido en el artículo 31 bis una persona jurídica sea responsable de los delitos comprendidos en este artículo, se le impondrá la pena de multa del triple al quíntuple del beneficio obtenido. Atendidas las reglas establecidas en el artículo 66 bis, los jueces y tribunales podrán asimismo imponer las penas recogidas en las letras b) a g) del apartado 7 del artículo 33 .

8. La provocación, la conspiración y la proposición para cometer el delito de trata de seres humanos serán castigadas con la pena inferior en uno o dos grados a la del delito correspondiente.

9. En todo caso, las penas previstas en este artículo se impondrán sin perjuicio de las que correspondan, en su caso, por el delito del artículo 318 bis de este Código y demás delitos efectivamente cometidos, incluidos los constitutivos de la correspondiente explotación.

10. Las condenas de jueces o tribunales extranjeros por delitos de la misma naturaleza que los previstos en este artículo producirán los efectos de reincidencia, salvo que el antecedente penal haya sido cancelado o pueda serlo con arreglo al Derecho español.

11. Sin perjuicio de la aplicación de las reglas generales de este Código, la víctima de trata de seres humanos quedará exenta de pena por las infracciones penales que haya cometido en la situación de explotación sufrida, siempre que su participación en ellas haya sido consecuencia directa de la situación de violencia, intimidación, engaño o abuso a que haya sido sometida y que exista una adecuada proporcionalidad entre dicha situación y el hecho criminal realizado». 
la reincidencia internacional, así como clausulas concursales y de exención de responsabilidad de la víctima.

Todo este conglomerado de institutos y conductas hubiera merecido de una regulación en varios artículos facilitando la interpretación de las diferentes previsiones requeridas por el legislador. Sin embargo, se ha optado por la redacción conjunta, lo que, por otro lado, ha evitado la inclusión de una serie de "bis" "ter" etc., tan criticada en el Código derogado y que, sólo estéticamente, no adorna al vigente.

La razón que se alega para la modificación, como he anticipado, es la completa transposición de la Directiva del 2011. Sin embargo, VILLACAMPA ESTIARTE advierte que no son estas las cuestiones de mayor peso para la reforma. Para esta autora, los cambios obedecen a necesidades técnicas ${ }^{48}$, aunque no parece que se hayan resuelto los mismos como ha expuesto IGLESIAS SKULJ $^{49}$, y veremos a lo largo de este trabajo.

En cuanto a los cambios, afectan a los verbos típicos (desaparece la conducta de alojar y se incluye la de intercambio y transferencia de control sobre la persona sometida a trata), a los medios empleados (se incluye la entrega o recepción de pagos o beneficios para lograr el consentimiento del traspaso de control y se clarifica el concepto de situación de necesidad o vulnerabilidad) y los fines de explotación (realización de actividades delictivas y matrimonios forzados) ${ }^{50}$. En relación con las agravaciones se reducen las de primer nivel que pasan de tres a dos, para alcanzar una mayor concreción en relación con las situaciones de peligro.

Paso pues a analizar el nuevo tipo.

48 Villacampa Estiarte, C.: "El delito...", cit., p. 403.

49 Iglesias Skulj, A.: "De la trata de seres humanos: artículo 177 bis CP", en González Cussac, J.L. (Director), Comentarios a la Reforma del Código penal de 2015, $2^{\mathrm{a}}$ edición, Valencia, 2015, pp. 595 y ss.

50 En el proyecto de reforma se recogían también cambios en relación con la trata con fines de explotación laboral que, finalmente, desaparecieron en el trámite del Senado. Se pretendía la desaparición de la referencia al trabajo forzoso y una reordenación de las formas de explotación laboral. Analiza esta cuestión, Villacampa Estiarte, C.: "El delito...", cit., pp. 408 a 410. 


\subsection{Aspecto objetivo}

\subsubsection{Bien jurídico}

La propia Exposición de Motivos de la LO 5/2010 fija como objeto de protección en el delito de trata de seres humanos la dignidad y la libertad de la persona. Bien jurídico que encaja perfectamente con la ubicación sistemática del art. 177 bis, en el Título VII bis, esto es, inmediatamente después de los delitos de tortura y contra la integridad moral y permite igualmente terminar con la polémica sobre cuál es el objeto de tutela en el delito del art. 318 bis. La doctrina había discutido si en dicho precepto se tutelaban simplemente, los intereses del Estado por controlar los flujos migratorios ${ }^{51}$ la correcta política migratoria $\mathrm{y}$ los derechos individuales de los inmigrantes ${ }^{52}$ las condiciones necesarias para que los extranjeros puedan ejercer plenamente sus derechos ${ }^{53} \mathrm{o}$ el derecho a la plena integración social del extranjero ${ }^{54}$. Ante los obstáculos que se planteaban a estas interpretaciones, la dignidad de los inmigrantes se presentaba como la opción más adecuada para la mayoría de la doctrina, dada la redacción del precepto ${ }^{55}$.

Ahora, parece que las conductas atentatorias contra la dignidad, o mejor, las que más gravemente pueden afectarla, son las ubicadas en el precepto que se estudia, y quedan protegidas

51 Expone esta cuestión Pérez Cepeda, A.I.: "Las normas penales españolas: cuestiones generales” en García Arán, M. (Coord.): Trata de personas..., cit., pp. 160 a 178.

52 García España, E. y Rodríguez Candela, J.L.: "Delitos contra los derechos de los extranjeros (art. 318 bis del Código penal)" en Actualidad penal, $\mathrm{n}^{\circ}$ 29, julio-2002, pp. 732 y 733.

53 Rodríguez Mesa, M.J.: Delitos contra los derechos de los extranjeros, Valencia, 2001, pp. 58 y 59. En el mismo sentido SAP Málaga (Melilla) 73/2005, de 28 de septiembre.

54 Serrano Piedecasas, J.R.: "Los delitos contra los derechos de los ciudadanos extranjeros" en Laurenzo Copello, P. (Coord.): Inmigración y derecho penal. Bases para un debate, Valencia, 2002, pp. 332.

55 Entre otros, León Villalba, F.J. (de): Tráfico de personas e inmigración ilegal, Valencia, 2003, p. 247 a 252. 
por su ámbito de punición, dejando el art. 318 para atender al interés estatal en controlar el flujo de inmigrantes, lo que debe ser revisado a la vista de lo expuesto anteriormente, y que no puede ser objeto de este trabajo.

\subsubsection{Sujetos}

En principio, el delito se presenta como común desde el punto de vista de los sujetos, por lo que cualquiera puede cometerlo, excepto en el tipo agravado del núm. 5 del art. 177 bis que incrementa la pena por la condición de autoridad, agente de la misma o funcionario del sujeto activo, o cuando éste pertenezca a banda organizada o asociación criminal aunque sea transitoria, según establece el núm. 6 .

Por lo que hace al sujeto pasivo, atendiendo a la propia definición de trata, puede ser cualquier persona nacional o extranjera ${ }^{56}$, puesto que, aunque lo habitual es que el traslado forzoso se produzca de un país a otro y el delito se configure como transfronterizo, nada obsta para que la víctima sea un nacional o, siendo extranjero, que la trata se produzca dentro del país sin necesidad de cruzar fronteras. Característica ésta que también permite diferenciar la trata de personas de la inmigración ilegal, donde, necesariamente, el sujeto pasivo ha de ser un extranjero y el delito transfronterizo ${ }^{57}$.

Además, esta interpretación viene reforzada por la referencia en la rúbrica a que la trata debe recaer sobre "seres humanos" y no solo sobre "ciudadanos extranjeros" como ocurre en la que intitula el delito del art. 318 bis, sin olvidar que la propia redacción típica alude a la "víctima nacional o extranjera"58. No obstante, determinadas cualidades en el sujeto pasivo (edad, es-

56 Critica esta diferencia Villacampa Estiarte, C.: "El delito...”, cit., pp. 414 y 415.

57 Vid., por ejemplo, SAP de La Coruña de 29 de julio de 2017.

58 Cugat Mauri, M.: "La trata de seres humanos", en Quintero Olivares, G. (Dir.): La Reforma penal de 2010. Análisis y comentarios, Pamplona, 2010, pp. 160 y 161 . 
pecial vulnerabilidad, etc.) hacen nacer otro tipo agravado (el previsto en el núm. 4).

\subsubsection{Objeto material}

El objeto de la acción es la persona sometida a trata, por lo que sujeto pasivo y objeto material coinciden en este delito, al igual que ocurre en los delitos contra las personas.

\subsubsection{Conductas típicas}

Como ya he adelantado, la estructura del precepto es compleja: se divide en un tipo básico en el que se recogen las conductas y los medios comisivos (núm. 1) acompañado de varios tipos agravados en función de las circunstancias que adornan al sujeto activo o al pasivo o por la conducta de puesta en peligro para la víctima o de pertenencia a asociación criminal. La concurrencia de unas y otras dan lugar a hiper-agravaciones no siempre conciliables con el principio de proporcionalidad.

\subsubsection{Tipo básico}

En el núm. 1 del art. 177 bis se describe la conducta de trata de personas mediante las acciones de captar, transportar, trasladar, acoger, o recibir. Con la reforma desaparece la referencia a alojar, lo que podría incluirse perfectamente en los verbos acoger o recibir ${ }^{59}$, aunque VILLACAMPA ESTIARTE ${ }^{60}$ lo achaca a que dicha conducta no se recoge ni en la Directiva 2011/36/ UE ni en el Convenio de Varsovia. En su lugar, se incluye el intercambio o transferencia de control a cambio de precio o beneficio. Con esta novedad se pretende acoger supuestos que no quedaban contemplados, desoyendo el Protocolo de Palermo y que acercan aun más la conducta a situaciones de esclavitud.

Estas acciones deben llevarse a cabo sobre persona nacional o extranjera, empleando violencia, intimidación o engaño o abusando de una situación, bien de superioridad del sujeto pa-

59 Iglesias Skulj, A.: "De la trata de seres humanos...", cit., pp. 597.

60 Villacampa Estiarte, C.: "El delito...", cit., p. 402 y ss. 
sivo, o bien de necesidad o vulnerabilidad de la víctima, tomando como referencia siempre que el sujeto pasivo ha de tener en algún momento contacto con el territorio español.

La conducta toma como punto de partida las previsiones de la Decisión Marco 2002/629 y las del Protocolo de la Convención de Naciones Unidas de 2000, produciéndose así la ordenada armonización que, como suele ser habitual, ha sido entendida por el legislador español como la transposición prácticamente acrítica de las recomendaciones supranacionales, dejando de lado la necesidad de que la integración ha de producirse teniendo en cuenta el resto de disposiciones penales relacionadas con la materia objeto de regulación. La pésima técnica legislativa no ha mejorado con la reforma de 2015, puesto que la Directiva en proyecto ya fue tomada en consideración en 2010 y el precepto sigue presentando deficiencias en su redacción.

Precisamente por ello, la fórmula legal se presenta como imprecisa y excesivamente amplia ${ }^{61}$, puesto que se incorpora como conducta a castigar aquella que se elabora desde la universalidad que ha de regir la orientación para la normación en varias realidades legislativas diferentes, afirmación que sigue siendo válida tras la entrada en vigor de la LO 1/2015.

Ciertamente, la conducta de trata se presenta como un proceso complejo y largo, en el que se producen intervenciones de diferentes sujetos en atención al momento o fase de desarrollo de la acción en el que nos encontremos y, por lo tanto, con muchas posibilidades de intervención en el hecho ilícito. Con la abundancia de verbos típicos se da cabida así a algunas de las situaciones imaginables de participación (aunque se plantea el inconveniente de los numeros clausus de dejar fuera otro tipo de comportamientos que podrían constituir trata) convirtiéndolas en actos de autoría directa ejecutiva, con independencia de si se ha producido la ejecución en la primera manifestación delictiva

61 Terradillos Basoco, J.: "Trata de seres humanos", en Álvarez García, J. y González Cussac, J.L., Comentarios a la Reforma penal de 2010, Valencia, 2010, pp. 209 a 211. 
(captación) o en la última (recibimiento). Por lo tanto, se adopta en este punto un concepto unitario de autor en virtud del cual los actos de colaboración se elevan a la categoría de autoría. Esto, por otro lado, obligará a que dichos actos de colaboración cumplan con las finalidades típicas previstas y participen de los medios comisivos descritos, pues, de otro modo, no podrán ser considerados como de autoría sino que habrán de reconducirse, en su caso, a las categorías generales de la cooperación necesaria o la complicidad (piénsese en el caso del que proporciona alojamiento, en un claro acto de acogida, sin haber empleado violencia ni intimidación y sin conocer la finalidad de explotación).

Por lo demás, la acción debe desarrollarse en territorio español o desde España, en tránsito o con destino a España, lo que implica que, en todo caso, en algún momento del proceso la víctima ha de estar físicamente en nuestro territorio. Esto conduce a la imposibilidad de castigar los supuestos de trata cometida en el extranjero, excepto en las hipótesis previstas en el art. 23 de la LOPJ ${ }^{62}$.

Ante esta previsión se muestra crítica VILLACAMPA ESTIARTE, quién entiende que la idea de mantener la trata vinculada a un territorio supone vulnerar los mandatos de incriminación contenidos en la normativa internacional y provoca, de nuevo, que no resulte sencillo diferenciar entre trata y tráfico ${ }^{63}$.

\section{A) Los verbos típicos}

La captación, desde un punto de vista gramatical estricto, supone que el sujeto se gana la voluntad del futuro tratado, siendo un acto previo que debe ir revestido de las notas de violencia, intimidación, engaño o abuso, según la dicción literal del precepto. En este punto, hay que hacer una mención especial a

62 Cugat Mauri, M., "La trata de seres...", cit., p. 161.

63 Situación que se hubiera agravado si hubiera desaparecido la referencia al territorio español en el art. 318 bis, cosa que finalmente no ha sucedido. Vid., Villacampa Estiarte, C.: "El delito...", cit., pp. 412 y 413. 
la aparición de las TIC, donde es fácil que se utilicen páginas de contactos para embaucar a las víctimas con el método del lover boy. Precisamente por ello entiendo que las más plausibles, atendiendo al matiz literal, será la comisión fraudulenta o abusiva, por lo que, en caso, por ejemplo, de rapto con violencia o con intimidación, no creo posible hablar de captación, y dicha conducta con la finalidad de explotación, extracción de órganos, etc., debería quedar fuera del ámbito de aplicación de la trata (castigándose, en su caso, por el correspondiente delito en concurso con el art. 177 bis según las previsiones de la cláusula concursal).

Si esto es así, se desoye una de las recomendaciones de la Disposición Marco, y también de la Directiva, que incluye entre los medios comisivos el propio rapto, como forma de coacción, fuerza o amenaza, en una confusión entre verbos típicos y medios comisivos que el legislador nacional ha salvado, pero olvidando incluirlo como acción típica que se caracteriza, precisamente, por la privación de libertad con finalidad de traslado mediante violencia o intimidación, error que no se ha subsanado con la reforma.

El transporte supone la acción y efecto de transportar o transportarse, esto es, llevar a alguien o algo de un lugar a otro, o lo que es lo mismo, trasladar. Desde un punto de vista gramatical pues, las dos referencias típicas estarían aludiendo al mismo supuesto: mover al tratado de un lugar a otro, con o sin cambio de país, por lo que siendo sinónimas resulta superflua su inclusión conjunta. En todo caso, de nuevo el traslado o el transporte se han de producir mediante violencia, intimidación o engaño o con abuso de posición activa/pasiva, por ser la figura un delito de medios determinados.

El acogimiento de nuevo ha de ser identificado desde el punto de vista literal con el recibimiento. Esto es, el hacerse cargo de la persona tratada. Es cierto que en la Disposición Marco se habla de acogida y subsiguiente recepción, con la idea, parece, de incluir tanto los actos de aquel que toma un primer contac- 
to con la víctima después de su captación o de su traslado, y la presenta a otro que realmente se hace cargo de la misma. En todo caso, considero que vuelve a resultar redundante la inclusión de ambas previsiones.

El alojamiento, como ya he anunciado desaparece en la nueva redacción, incluyéndose este acto de colaboración entre los de acogida o recepción.

El intercambio o transferencia de control a cambio de pagos o beneficios, que aparece como novedad, ya venía recogido en el art. 3 del Protocolo de Palermo y en el art. 2 de la Directiva. Se trata de dotar de cobertura a los casos de venta, permuta o alquiler entre sujetos que no han tenido que ver con la captación, recepción o transporte.

\section{B) Los medios comisivos}

Todas estas acciones han de llevarse a cabo mediante alguno o algunos de estos medios: violencia, intimidación, engaño o abuso de situación, bien de dominio por parte del sujeto activo, o bien de vulnerabilidad por parte de la víctima.

Atendiendo a los criterios clásicos de interpretación de estos medios comisivos comunes a los delitos considerados violentos (robo con violencia, agresiones sexuales, etc.) la violencia ha de interpretarse como vis física, la fuerza física externa que se aplica sobre aquel que ha de desplazarse. Igualmente, la intimidación comprende la vis psíquica o compulsiva, esto es, la utilización de presión psicológica mediante la amenaza de un mal inminente y grave que genera sentimiento de inseguridad en aquel que la padece y que puede recaer sobre sí mismo o sobre terceros, incardinándose dentro de ella tanto los casos en los que el consentimiento se obtiene doblegando la voluntad de la víctima con amenazas como con coacciones.

Por lo que hace a la posición de situación de superioridad del sujeto activo, se trata de que exista una desigualdad de fuerzas entre la víctima y el sujeto activo. El sujeto activo se encuentra en una posición de ventaja, frente al sujeto pasivo 
que, precisamente por ello, está en situación de vulnerabilidad. Por lo que hace a la situación de necesidad de la víctima, hasta ahora se ha considerado que ni la vulnerabilidad ni la necesidad pueden identificarse como con la situación objetiva de necesidad por las circunstancias personales o económicas de la víctima, ni políticas del país del que proceda cuando se trate de víctima extranjera.

Y recuérdese que, en caso de traslado voluntario, no entraríamos en las conductas de trata, lo que se ve con más detenimiento al analizar el consentimiento y su validez.

Ello resulta especialmente importante si se toma en consideración que no cualquier persona que quiere trasladarse de un lugar a otro, de un país a otro, por vivir una situación de desigualdad económica o social, ha de hacerlo necesariamente en una situación de incapacidad absoluta para tomar la decisión. Ser inmigrante no es sinónimo de ser víctima, como acertadamente señala MAQUEDA ABREU ${ }^{64}$. No es este el sentido que quiere dar la Decisión Marco cuando aclara que hay abuso de "autoridad" o "situación de vulnerabilidad" cuando la persona no tiene una "alternativa real y aceptable salvo someterse al abuso", y que parece estar refiriéndose, precisamente, a esas circunstancias, con lo que se retoma una idea que apareció en la primera redacción del art. 318 bis, y que fue criticada doctrinalmente ${ }^{65}$.

El engaño, supone el empleo de artificios mediante los cuales se induce a error sobre el hecho de la trata al sujeto que ha de desplazarse. Ha de ser capaz para conseguir el consentimiento que de otro modo no se tendría, por lo que objetivamente debe ser adecuado y suficiente para dicha finalidad, asemejándose en su interpretación a la que se realiza en sede de estafa.

Por lo tanto, estamos hablando de medios idóneos para conseguir neutralizar la voluntad de la víctima y dirigidos pre-

64 Maqueda Abreu, M.L.: “A propósito...”, cit., pp. 1250 y ss.

65 García Arán, M.: "Los tipos penales acogedores del tráfico de personas", en García Arán, M (Coord.), Trata ..., cit., pp. 206 y ss. 
cisamente a dicho fin y a cumplimentar alguna de las acciones descritas (captación, traslado, etc.). Por ello, las violencias gratuitas, o el engaño para reforzar un consentimiento previo no formarían parte del delito ${ }^{66}$.

La cuestión es que estas formas de comisión deben relacionarse con los verbos típicos reseñados, lo que nos lleva, como ya he adelantado, a que en ocasiones dentro de una misma cadena delictiva se planteen actuaciones que entrarían de lleno en el tipo y otras que, cumplimentando alguno de los requisitos típicos (la acción) no se formulen completamente al no concurrir alguno de los medios comisivos o por desconocerse la finalidad perseguida. El problema fundamental será como articular las distintas imputaciones de los sujetos que participan en el hecho, atendiendo a estas circunstancias.

\section{C) La finalidad perseguida}

Atendiendo a la distinción entre traffiking y smuggling, y por lo tanto tomando en consideración el entendimiento de la trata de personas como un acto de traslado forzoso, cualquiera de las conductas descritas llevadas a cabo a través de los medios expuestos, además ha de ir acompañada de la persecución de alguna de estas pretensiones: la imposición de trabajos o servicios forzados, la esclavitud o prácticas similares a la esclavitud o a la servidumbre o la mendicidad, la explotación sexual, incluida la pornografía, la explotación delictiva, el matrimonio forzoso y la extracción de sus órganos corporales.

La inclusión del matrimonio forzoso materializa una de las peticiones doctrinales pero, de nuevo, se incluye en un elenco cerrado que impide contemplar dentro de este ámbito subjetivo supuestos distintos de los expresamente previstos, como por ejemplo, la realización de ensayos clínicos en la víctima ${ }^{67} \mathrm{o}$ el reciente fenómeno de captación de jóvenes por grupos islamistas radicales con la finalidad de engrosar las filas de células

66 Terradillos Basoco, J.: "Trata...", cit., p. 210.

67 Cugat Mauri, M.: "La trata de...", cit., p. 161. 
terroristas, o para fines de maternidad subrogada o las adopciones ilegales, que quizás deberían ser tomadas en consideración si se atiende a la desaparición de más de 10.000 niños entre los refugiados sirios, con sospecha de que están siendo sometidos a trata. De nuevo, la existencia de una lista cerrada pone de manifiesto la aparición de lagunas que podrían solventarse con el establecimiento de cláusulas generales que abarcaran todas las situaciones.

La finalidad de someter a la víctima a trabajos o servicios forzosos es la que motivó la derogación del núm. 1 del art. 311; la consecuencia de tal derogación, afirma TERRADILLOS $\mathrm{BASOCO}^{68}$, es que cuando el favorecimiento de la inmigración ilegal de trabajadores no alcance la gravedad suficiente para ser incardinado en los medios previstos en el art. 177 bis deba reconducirse al 318 bis lo que resulta, para este autor, inadecuado desde el punto de vista sistemático. En todo caso estamos hablando de una situación de explotación relevante, en la que el trabajador se ha visto sometido sin su consentimiento, bien por no haberlo emitido, bien por estar afectado de vicios que lo invaliden.

La situación de esclavitud o prácticas similares, que se equiparan a la servidumbre o la mendicidad, ha de interpretarse a la luz de la descripción de la Directiva. En el párrafo segundo del núm. 1 del art. 2 se dice que deben castigarse las conductas de captación, transporte, acogimiento, recepción o traspaso de control, que se realicen mediante la concesión u obtención de pagos o beneficios para conseguir el consentimiento de una persona que posea el control sobre otra persona. Esto es, se trata de conductas cercanas a la definición clásica de esclavitud, en la que las notas de ejercicio de poder dominical y transacción comercial de una persona sobre otra son las que permiten reconocer dicha situación.

Esta interpretación imprescindible hasta ahora, resulta ya menos necesaria tras la inclusión expresa de los supuestos de 68 Terradillos Basoco, J., “Trata...”, cit., p. 208. 
traspaso bajo precio, lo que facilita el entendimiento de las prácticas de esclavitud que implican una verdadera actitud dominical de una persona sobre otra: la venta de niñas y mujeres para matrimonios forzosos, los ensayos clínicos o farmacéuticos, la venta de niños para formar parte de tropas de guerra, o cualquier otra finalidad que implique una transacción económica y despliegue de facultades dominicales.

La referencia a la explotación sexual incluida la pornografia, ha de llevar la exégesis necesariamente por los medios comisivos, y a incluir exclusivamente la prostitución forzada quedando fuera del ámbito de aplicación del precepto la inmigración clandestina dirigida al ejercicio voluntario de la prostitución en el país de destino que, en su caso, deberán castigarse por los correspondientes tipos de atentados contra los derechos de los ciudadanos extranjeros o contra la libertad o indemnidad sexual.

La explotación para realizar actividades delictivas se ha incorporado como consecuencia de la previsión expresa del art. 2.2. de la Directiva 2011/36/UE, aunque la doctrina ya la incluía en el concepto de servicios forzados ${ }^{69}$.

El tráfico de personas para extraer sus órganos ha de relacionarse con el nuevo tipo contenido en el art. 156 bis, con el que se plantearán problemas concursales, atendiendo a las conductas de promoción, favorecimiento y facilitación de la obtención o el tráfico ilegal de órganos humanos, no siempre sencillos de resolver.

Por último, se incluye como finalidad de explotación la celebración de matrimonios forzados que, como he dicho más arriba, venía siendo reclamada por la doctrina, aunque se sobreentendía incluida entre las prácticas de esclavitud o semejantes a la esclavitud, o como forma de explotación sexual.

En estos momentos habrá que poner en relación está previsión con el delito de coacción específica de matrimonio forzoso prevista en el art. 172 bis.

69 Pomares Cintas, E.: "El delito de trata de seres humanos con finalidad de explotación laboral”, en EPC, 13-15, 2011, p. 21. 
Hay que tomar en consideración que la pena del art. 172 bis es sensiblemente inferior a la prevista en el art. 177 bis, lo que plantea problemas de proporcionalidad, por un lado, y concursales por otro.

En principio, se planteará un concurso de delitos entre el art. 172 bis y el art. 177 bis cuando el matrimonio se celebre efectivamente, y se den los supuestos exigidos por la trata.

Por su parte, la conducta del art. 172 bis 2 entra, a mi modo de ver, en concurso de leyes con la trata prevista en el art. 177 bis, quedando para la coacción aquellas situaciones que no puedan acomodarse en la trata, que prevalecerá por especialidad adquiriendo así el art. 172 bis naturaleza de tipo residual.

\section{D) El consentimiento}

La falta de consentimiento del sujeto pasivo en su traslado constituye el elemento central a la hora de reconocer un caso de tráfico de personas y diferenciarlo de uno de tráfico de inmigrantes.

En este sentido, ya he expuesto como los medios comisivos han dirigirse teleológicamente a doblegar la voluntad de la víctima, es decir, a realizar su traslado en contra de su voluntad u obteniendo su consentimiento de manera fraudulenta.

El núm. 3 del art. 177 bis recuerda que el consentimiento emitido bajo la presión de los medios indicados resulta irrelevante, lo que no puede ser de otra manera, y se incluye, de nuevo, por una transposición directa de las previsiones de la Decisión Marco.

Más adecuada, aunque incompleta, resulta la disposición contenida en el núm. 2 del art. 177 bis relativa a la validez del consentimiento de los menores. Cuando se trate de menores de edad (esto es, de menores de 18 años) el consentimiento para el traslado será siempre invalido, aunque no se obtenga a través de los medios descritos en el núm. 1. Ciertamente, la incapacidad del menor para tomar decisiones en este ámbito justifica sobradamente esta indicación. Lo que no resulta tan adecuado es que 
la misma vaya referida exclusivamente a los fines de explotación. Como bien dice TERRADILLOS BASOCO ${ }^{70}$, esta incongruencia se debe nuevamente a la precipitación del legislador que, en esta ocasión, sí podía haber hecho un traspaso directo de la normativa europea y hubiera evitado tener que forzar la exégesis, puesto que, como resulta obvio, habrá que entender que todos los fines previstos en el tipo básico quedan incluidos. Reparo en el que tampoco se ha caído a propósito de la reforma de 2015.

Pero es que, además, no se explica por qué no existe una equiparación entre el menor y el incapaz que no aparece explícitamente en el precepto. La única razón se puede encontrar en que habitualmente las normas europeas no aluden a los incapaces, y reconducen esta situación a las personas especialmente vulnerables, pero el legislador, en el proceso de armonización, debería haber considerado esta peculiaridad, y haber hecho referencia a los sujetos cuyas condiciones se contemplan en el art. 25 del Código Penal. En todo caso, tampoco será válido el consentimiento emitido por los incapaces, en la medida en que el mismo resulta viciado por falta de capacidad ${ }^{71}$.

\subsubsection{Tipos agravados}

\section{A) En atención al sujeto pasivo}

El núm. 4 del art. 177 bis agrava en dos apartados el hecho (antes tres) e impone una sanción superior en grado cuando se ponga en grave peligro a la víctima, o cuando esta sea menor de edad o si se encuentra en una situación de especial vulnerabilidad por razón de enfermedad, discapacidad, o por su situación personal.

Si concurre más de una, la pena se aplicará en su mitad superior.

En el primer caso, el fundamento de la agravación radica en el peligro (grave) y concreto para bienes jurídicos esenciales

70 Terradillos Basoco, J., “Trata...," cit., pp. 210 y 211.

71 Algo similar ocurre en el delito de sustracción interparental de menores. 
como la vida, la salud o la integridad, que genera un incremento de injusto.

En los otros dos supuestos, es necesario realizar una interpretación sistemática con el núm. 2 para deslindar cuándo se aplica uno u otro tipo. Dado que en el tipo básico se castiga cuando el sujeto pasivo es menor con independencia de los medios empleados para obtener el consentimiento, la agravación solo podrá apreciarse cuando dichos medios sí hayan sido utilizados, pues de otro modo el primer tipo resultaría vacío de contenido. Lo mismo cabe apreciar respecto de la situación de especial vulnerabilidad. Cuando ésta se haya utilizado para fundamentar el tipo básico, no procederá su apreciación en el agravado, pues de otro modo se vulneraría el principio ne bis in ídem. Por lo demás, el tratamiento de los incapaces deberá reconducirse a la situación de especial vulnerabilidad de la víctima por incapacidad.

La situación de estado gestacional como condición de vulnerabilidad se ha introducido en la reforma operada por la LO $1 / 2015$, ampliando y reafirmando la naturaleza de números clausus del precepto, sin ayudar, a mi modo de ver, a una mejor aplicación típica. Tampoco redunda en una mejora de la tutela del bien jurídico la adjetivación de la situación como "situación personal", pues como ha puesto de manifiesto VILLACAMPA ESTIARTE $^{72}$, que la referencia sea a situaciones personales resulta demasiado restrictivo, dado que la vulnerabilidad puede derivar, como ha establecido el CGPJ, de situaciones sociales, familiares, económicas o de otra naturaleza.

El fundamento de la agravación en estos casos se sustenta, justamente, en la disminución de defensa de los sujetos pasivos por sus especiales características, que explica la mayor pena, aunque ciertamente pueda resultar desproporcionada.

\section{B) En atención al sujeto activo}

El incremento de pena obedece en el núm. 5 a la condición de autoridad o funcionario del sujeto activo del delito, que

72 Villacampa Estiarte, C.: "El delito...”, cit., pp. 410 y 411. 
merece la pena superior en grado y una inhabilitación absoluta de seis a doce años, lo que desplaza la aplicación de la agravante genérica. Si se añade alguna (una o más) de las previstas en el número anterior la pena se eleva a la mitad superior. Lógicamente el aumento en la sanción responde al abuso de la posición que ocupa, que proporciona una mayor facilidad para cometer el hecho, lo que lleva a traer las reflexiones apuntadas anteriormente para deslindar la aplicación del tipo básico y el agravado. Por ejemplo, si la condición de funcionario ha sido determinante para obtener el consentimiento viciado y se ha cumplimentado el requisito de abuso de superioridad, no se podrá aplicar la agravación. Si el medio comisivo ha sido otro (la violencia) sí será posible incriminar por el supuesto más grave.

Para el concepto de funcionario público y autoridad hay que acudir al art. 24 del Código penal.

Otra circunstancia que permite subir la pena en un grado es la integración del sujeto activo en organización criminal o asociación a lo que se suma la pena de inhabilitación especial durante el tiempo de la condena. La mitad superior corresponderá cuando, además, concurra alguna de las circunstancias del núm. 4, mientras que si se da el caso de que el sujeto sea funcionario público, se aplicará la pena prevista en el núm. 5 en su mitad superior.

Para saber cuándo la asociación para delinquir constituye organización criminal, hay que acudir a la definición que ofrece el art. 570 bis 1 último párrafo.

Tradicionalmente se ha venido exigiendo la presencia de las notas de organización y permanencia, para evitar incluir el mero acuerdo de voluntades para cometer el delito que podría reconducirse al ámbito de la conspiración para delinquir. La organización requiere de cierto grado de jerarquía y reparto de funciones y un plan de actuación conjunta, mientras que la permanencia supone cierta estabilidad para la realización de los delitos. 
Sin embargo, el art. 177 bis añade a la idea de organización criminal la de asociación, aunque sea transitoria, dedicada a "tales actividades". Teniendo en cuenta que el delito de trata de personas necesita para su comisión de una serie de sujetos que intervengan en cada fase (captación, transporte, acogida), difícilmente se podrá aplicar el tipo básico, salvo que se entienda, con TERRADILLOS BASOCO ${ }^{73}$, que la dedicación a tales actividades exige algo más que la asociación esporádica para un solo acto de trata dilatado en el tiempo, que debe quedar fuera del ámbito de lo agravado. Además, la idea de asociación no debe desvincularse tampoco de la de jerarquía y reparto de funciones y unidad de propósito propio de toda asociación, interpretación que se refuerza por la presencia en el mismo art. 177 del castigo de los que ocupen puestos de jefes, encargados, etc.

Ciertamente, el aprovechamiento de las redes de criminalidad organizada para la realización de la conducta genera una mayor facilidad para la comisión, lo que hace que exista una especial preocupación en el ámbito internacional sobre el castigo de la utilización de estas organizaciones, lo que se plasma en el establecimiento de la agravación y en la previsión de consecuencias penales también para el caso de la comisión por parte de una persona jurídica.

Junto a ello, si el sujeto activo ocupa un cargo de jefe, administrador o encargado de dicha organización, se le aplica la pena en su mitad superior siendo facultativo llegar hasta la inmediatamente superior en grado. En este último caso, si, además, concurre la circunstancia del núm. 4 o el sujeto es funcionario o autoridad, la imposición de la pena superior en grado resulta imperativa, creándose así un tipo super-agravado que dispara la pena equiparándola a la del homicidio.

73 Terradillos Basoco, J., “Trata...”, cit., pp. 213 y 214. 


\section{Aspecto subjetivo}

El delito es eminentemente doloso, siendo imposible la comisión imprudente, no sólo por no estar prevista específicamente, sino por la presencia de elementos subjetivos (finalidad de explotación, someter a esclavitud, mendicidad, extracción de órganos, etc.) que impiden la comisión culposa.

\section{Formas de aparición del delito}

\subsection{Actos preparatorios punibles}

Quedan expresamente previstos en el número ocho del art. 177 bis y castigados, como es habitual en estos casos, con pena inferior en uno o dos grados a la establecida para la consumación del delito.

Esta previsión, que no venía exigida por la Decisión Marco 2002/629 (que sólo habla de la inducción, la complicidad y la tentativa), sí queda justificada por la gravedad de las conductas de trata, que legitima el adelantamiento de la barrera punitiva.

Otra cuestión es que fuera necesaria su inclusión, atendiendo a la redacción del art. 570 bis, donde se recoge el castigo de la promoción, constitución, organización, coordinación o dirección de una organización criminal, con la finalidad de cometer delitos graves y, específicamente, la trata de seres humanos, caso para el cual se establece una pena mayor. Al entender de TERRADILLOS BASOCO ${ }^{74}$ en el 570 bis ya quedan contemplados los actos preparatorios político-criminalmente relevantes, siendo cierta esta aseveración para el caso de que se actúe a través de una organización criminal, lo que, por lo demás, será lo habitual dada la infraestructura que se precisa para cometer el delito y las exigencias para entender que existe tal asociación (como ya se ha visto basta que sean más de dos personas, aunque la alianza sea con carácter transitorio).

74 Terradillos Basoco, J., “Trata...”, cit., p. 215. 
Aun así, considero que no resulta desacertada la previsión, si se establece para comprender todos los casos de provocación, proposición y conspiración para delinquir, pues en esos primeros momentos de preparación del delito no necesariamente debe darse ya la situación de organización criminal o asociación para delinquir, ni los supuestos de formación de una organización para cometer el delito, previstos en el art. 570 bis, han de suponer siempre una forma de conspiración, provocación o proposición.

\subsection{Formas imperfectas de ejecución}

La consumación se produce en el mismo momento en que el sujeto es sometido a trata, esto es, cuando se da cumplimiento a las conductas descritas por los verbos típicos: captación, transporte, traslado, acogimiento, etc. Dado que la trata de seres humanos se plantea como un delito a cometer en varias fases, cada sujeto responderá de "su" consumación y, por tanto, como autor, cuando se realice su acción típica. Esto es, el que se dedica a captar, consumara el delito con dicha captación con fines de explotación, etc. y mediante los medios comisivos previstos (violencia, engaño, etc.), mientras que el que ofrece el acogimiento, no aparecerá como autor (coautor) hasta el momento en que llegue el sujeto tratado al lugar de acogimiento, lo que no quiere decir que de interrumpirse antes la dinámica comisiva por causas ajenas a la voluntad de los autores, este último no pueda responder como cooperador necesario del delito de trata y, por lo tanto, como autor, siquiera sea formal ${ }^{75}$.

Ningún problema hay en la admisión de la tentativa atendiendo a las reglas generales de nuestro texto penal, por lo que no era necesario establecer ningún tipo de previsión específica, tal y como requiere la Decisión Marco 2002/629 para los ordenamientos en los que sí sea preciso. Rigen las reglas generales y es posible tanto la tentativa acabada como la inacabada.

75 En este sentido, se puede ver la Sentencia del Tribunal Supremo de 18 de mayo de 2016, en la que se afirma que se trata de un delito doloso de consumación anticipada en el que basta la concurrencia del mismo el traslado con el fin de explotación sin que se llegue a la misma. 


\subsection{Autoría y participación}

La Decisión Marco 2002/629 también pedía a los Estado que establecieran previsiones especiales para el castigo de la complicidad, lo que en nuestro ordenamiento jurídico no resulta necesario pues las reglas generales de la participación permiten incriminar los actos de colaboración. La cuestión, sin embargo, radica en que siendo el delito de aquellos que manejan un concepto unitario de autor, y de los que elevan a esta categoría actos de participación, será difícil encontrar supuestos que queden al margen de la autoría, pues los actos de participación quedan como actos ejecutivos por mor de la descripción de los verbos típicos, siendo difícil su aplicación.

\subsection{Responsabilidad de las personas jurídicas}

La inquietud internacional y europea por atajar la delincuencia organizada se manifiesta en la solicitud a los Estados de incluir en sus legislaciones consideraciones específicas para cuando determinados delitos, entre ellos el de trata de personas, se cometan por una persona jurídica. La Decisión Marco así lo pide y el legislador lo ha contemplado en el núm. 7 del art. 177.

El propio precepto remite a lo dispuesto en el art. 31 bis del Código penal en relación con la comisión delictiva por parte de las personas jurídicas, donde se establece su responsabilidad y se define el modo de actuación. Cuando la trata se produzca en este marco, la pena aplicable será de multa del triple al quíntuple del beneficio obtenido. La cuestión en este punto, como apunta TERRADILLOS BASOCO ${ }^{76}$ vuelve a ser la precipitación del legislador que no ha considerado que la trata en sí no genera beneficios; los beneficios derivan de los actos posteriores de explotación, imposición de servicios o trabajos forzados, mendicidad o extracción de órganos. De nuevo se confunde el instrumento para la explotación con la explotación misma y nada se ha hecho en la reforma de 2015 por solventarlo.

76 Terradillos Basoco, J., “Trata...”, cit., p. 215. 
Por lo demás, también se contempla la posibilidad de aplicar las penas dispuestas en el art. 33 apartado 7 letras b, a, g (disolución de la persona jurídica, suspensión de actividades, clausura de locales y establecimientos, prohibición de realizar actividades de futuro relacionadas con las que han provocado el delito, inhabilitación para obtener subvenciones y ayudas públicas, intervención judicial para salvaguardar los derechos de los trabajadores).

\section{Cláusula concursal}

La instrumentalidad del delito de trata y, por lo tanto, su concurrencia con otras figuras hace adecuada la presencia de esta cláusula concursal en el núm. 9. Con ella se puede establecer un concurso de delitos entre la propia figura de trata y las que correspondan por las lesiones específicas que se generen, tanto en su realización como al completar los fines perseguidos; así, será posible el concurso de la trata con los delitos de homicidio, lesiones, extracción de órganos para su trasplante, prostitución, pornografía, agresión o abuso sexual, derechos de los trabajadores, derechos de los ciudadanos extranjeros, los matrimonios forzosos ${ }^{77} \mathrm{y}$ cualquier otro que pueda concurrir.

Al hablar de los problemas que genera la confusión entre trata y esclavitud ya he puesto de manifiesto cómo se puede afectar el Principio de proporcionalidad en estos casos.

Junto a ello, no hay que olvidar que la jurisprudencia se ha pronunciado sobre cuántos delitos se han cometido si son más de una las personas sometidas a la trata, quedando claro que habrá tantos delitos como personas traficadas, en concurso real, tomando en consideración que el sujeto pasivo es individual y no colectivo ${ }^{78}$.

77 Sobre este reciente delito y la relación concursal con la trata se puede ver Esquinas Valverde, P.: "El delito de matrimonio forzado (art. 172 bis CP) y sus relaciones concursales con otros tipos delictivos, en $R E C P C, 20-32$ (2018), pp. 29 y 30.

78 Siguiendo el Acuerdo del Pleno no jurisidiccional del Tribunal Supremo de 31 de mayo de 2016. También SSTS 538/2016, de 17 de junio y 77/2019, de 12 de febrero. 
Además, el delito de trata no absorbe el de inmigración ilegal, atendiendo a los diferentes bienes jurídicos protegidos y a la presencia o no de consentimiento ${ }^{79}$.

\section{Consecuencias jurídicas}

\subsection{Reincidencia internacional}

Al igual que sucede en figuras tales como el tráfico de drogas, la prostitución o la falsificación de moneda, se equipara la condena emitida por un tribunal extranjero a la dictada por España a los efectos de la reincidencia, siendo así posible calificar al sujeto como reincidente aun en el caso de no haber sido condenado en nuestro país.

\subsection{Cláusula de exención de responsabilidad de la víctima}

En el núm. 11 del art. 177 bis se recoge una excusa absolutoria para la víctima de la trata, por aquellos ilícitos que lleve a cabo en situación de explotación, y por lo tanto, bajo violencia, intimidación, abuso o engaño. Es decir, no por los delitos que se produzcan durante el traslado o el proceso de trata, sino en el momento ulterior de explotación. Esto genera cierta indeterminación, que unida a la petición de proporcionalidad entre la situación de sometimiento y el hecho realizado, deja en manos de los operadores jurídicos la concreción de los términos para fijar esa proporcionalidad, con los problemas de seguridad jurídica que siempre generan estas abstracciones.

\section{La necesidad de una ley integral de trata de seres huma- nos. A modo de conclusión}

Visto todo lo anterior, queda por reflexionar si es necesaria o no, una ley integral de trata de seres humanos. Lo primero

79 STS 77/2019, de 12 de febrero. 
sería clarificar qué es una ley integral y, para ello, creo que hay que atender a las normas así denominadas que se contienen en nuestro ordenamiento jurídico.

La Ley Orgánica 1/2004, de medidas de protección integral contra la violencia de género, presentó una nueva forma de legislar que se apoyaba en la necesidad de proporcionar una "respuesta global a la violencia que se ejerce sobre las mujeres", en atención a las peticiones de diferentes organismos internacionales $^{80}$. De este modo, se estructura una norma que recoge los diferentes aspectos que afectan al fenómeno en todas sus vertientes, con una visión transversal que atiende tanto a aspectos preventivos, educativos, sociales y de asistencia a las víctimas, como a la normativa en materia procesal, laboral, administrativa, civil, penal y penitenciaria.

De este modo aparece una nueva forma de "codificación" que persigue la unificación de las medidas a adoptar por el Estado en el caso de un fenómeno de compleja resolución, centrando la atención en las víctimas y sus cuidados.

Esta manera nueva de legislar ha tenido reflejo en otras normas, como por ejemplo, la Ley 12/2008, de 3 de julio de 2008, de la Generalitat Valenciana, de protección integral de la infancia y la adolescencia ${ }^{81}$, la Ley $3 / 2016$, de 22 de julio, de protección integral contra la LGTBIfobia y la Discriminación por razón de orientación sexual en la Comunidad de Madrid, o los diferentes proyectos y propuestas de ley que se han sucedido en los últimos tiempos en materia de memoria histórica, libertad sexual o protección de la infancia. Todas ellas se construyen sobre la necesidad de recopilar el acervo normativo existente en una materia y dotarlas de una visión pluridisciplinar y global que permita una mejor resolución de los conflictos que regulan.

En esta órbita, se inscribe la petición de la creación de una Ley integral de trata de seres humanos.

80 Exposición de motivos de la Ley, II.

81 Derogada y sustituida por la Ley 26/2018, de 21 de diciembre, de derechos y garantías de la infancia y la adolescencia de la Comunidad Valenciana. 
Además de la creación en el seno de la Comisión de Igualdad de una subcomisión para la lucha contra la trata de seres humanos con fines de explotación sexual, a propósito del Pacto de Estado contra la violencia de género. Dicha subcomisión ha de tener, entre sus objetivos, el análisis de los mecanismos de lucha activa contra el tráfico y trata de seres humanos así como de la prostitución entendida como explotación y esclavitud, donde se plantea la necesidad de dotar de un tratamiento integral a los problemas de trata de seres humanos, con la disputa sobre si la misma ha de referirse en general a todas las víctimas de trata o si, por el contrario ha de tener una visión específica en materia de trata con fines de explotación sexual ${ }^{82}$.

Como he dicho más arriba, hasta hace bien poco, la mayoría de los mandatos supranacionales en la materia ponían el foco de atención en la punición del proceso de traslado, dejando en segundo plano a las personas que sufren el delito que, además de su situación de vulnerabilidad, tropiezan con dificultades adicionales a las víctimas de otros delitos, como son la diferencia de idioma, cultura o religión, lo que ha conducido, en no pocas ocasiones a no realizar una correcta identificación de la víctimas de trata al confundirlas con inmigrantes ilegales que se desplazan voluntariamente. Ante esta tesitura, y visto el problema desde un punto de vista global y no solo penal, sí considero que se impone buscar soluciones que permitan una mejor protección de las víctimas de trata, al margen del proceso punitivo, y la ley integral podría ser una solución. Sería el lugar donde establecer criterios que permitan proporcionar una visión transversal, para evitar, como ya he dicho, los procesos de revictimización o de exclusión de la protección directamente.

He advertido en la introducción que la Directiva 2011/36/ UE de 5 abril de 2011 exige ese tratamiento global, y aunque es

82 Vid., Plan integral de lucha contra la trata de mujeres y niñas con fines de explotación sexual (2015-2018). Plan Del Ministerio de Sanidad, Servicios Sociales e Igualdad, disponible en http://www.violenciagenero.igualdad. mpr.gob.es/planActuacion/planContraExplotacionSexual/docs/Plan_Integral_Trata_18_Septiembre2015_2018.pdf 
cierto que nuestro ordenamiento jurídico contempla la tutela de la víctima en la Estatuto de la Víctima ${ }^{83}$, y en el texto penal se establece una cláusula de exención de responsabilidad cuando la víctima se ha visto obligada a cometer hechos delictivos, no es menos cierto que la realidad demuestra que siguen produciéndose situaciones en las que las personas sometidas a trata sufren un proceso de revictimización al ser detenidas, procesadas e incluso condenadas o expulsadas por la dificultad en su identificación y la falta de medios que permitan paliar su especial vulnerabilidad.

Junto a ello, existe una gran dispersión normativa que tiene que ver con la propia naturaleza de la acción y los sujetos implicados en ella (personas generalmente extranjeras que pueden haber entrado en el país legal o ilegalmente, y que pueden estar siendo explotadas habiendo tenido conocimiento o no de la actividad que iban a desarrollar, aunque nunca de las condiciones en las que se iba a producir dicha actividad).

La necesidad de hacer una reflexión conjunta que lleve a unificar criterios y permita establecer medidas de prevención, educación, asistencia social, jurídica y sanitaria, etc., podría favorecer una reducción en la comisión del ilícito y, desde luego, dotar de mejor tutela a las personas sometidas al proceso de traslado involuntario. Por lo tanto, considero que sí podría pensarse en esta vía.

La siguiente cuestión radica en si dicha ley deber ir referida a todas las clases de trata o ha de tener una especial relevancia en relación con la que sufren las mujeres.

Ciertamente, ya he dicho también que la trata afecta tanto a hombres como a mujeres, pero no es un fenómeno objetivamente neutro desde el punto de vista del género, aunque no se refiere solo a la explotación sexual, sino que las mujeres víctimas de trata pueden ser explotadas en otros ámbitos, como el laboral (sobre todo en empleos en el campo, o como cuidadoras de ancianos o enfermos), en la gestación subrogada inconsenti-

83 Ley 4/2015, de 27 de abril, del Estatuto de la víctima del delito. 
da, etc. En todo caso, ello no es óbice para que queden excluidos de la protección integral los varones víctimas de trata.

También he advertido que el informe GRETA, precisamente lo que reprocha a España es que no ha puesto los medios adecuados para la lucha contra la trata de seres humanos en general, centrándose en exceso en la trata con fines de explotación sexual. Esta razón es importante, pero también lo es que, aunque es cierto que un importante número de mujeres que ejercen la prostitución son víctimas de trata, no lo es menos que no se debe confundir prostitución y trata, como he dicho, entre otras razones porque ello implica confundir el proceso de traslado inconsentido con la explotación, con todos los problemas que ello plantea y que han sido puestos de manifiesto por la doctrina y explicados anteriormente.

Tampoco creo que fuera conveniente fusionar los problemas de trata de seres humanos en la LO 1/2004; no solo por las razones apuntadas en relación con la diversidad de victimas (hombres y mujeres), sino también porque los problemas de ambos fenómenos son diferentes y las soluciones, por tanto, también han de serlo. Crear una ley integral para dotar de unidad al conjunto, con la inclusión de elementos distorsionadores, sería contradictorio en sí mismo.

Por lo demás, y desde un punto de vista estrictamente penal, no hay que olvidar que los fines de explotación son tantos y tan variados que sería necesario tener en cuenta la inclusión de una clausula abierta que sustituyera al casuístico art. 177 bis del Código penal para permitir incluir cualquier clase de tráfico de personas en contra de su voluntad, con independencia de la explotación a la que vayan a ser sometidos y valorar la creación de un delito de esclavitud específico que solventara los problemas de proporcionalidad que se constatan en el caso de que la trata vaya seguida de explotación, y que no ha sido tomado en cuenta por el legislador a la hora de integrar la normativa supranacional -en concreto la Directiva- en el texto punitivo. 
Sin embargo, no creo que hubiera ningún problema en que la Ley integral para la tutela de las víctimas de trata introdujera elementos de género en su regulación para los casos en los que se deba prestar cuidado y atención a víctimas que, por la específica explotación a la que se destinaban (o que sufrieron) deban recibir un tratamiento diferencial y personalizado. Dotar de una perspectiva de género es algo que puede permitir establecer criterios de atención específica cuando ello sea necesario sin pasar por la creación de una norma independiente. Desde luego, no creo que dicha perspectiva obligue, en ningún caso, a establecer una mayor punición si en dicha ley integral se prevén cambios en las sanciones penales.

De nuevo, el uso del instrumento penal no puede ser la excusa que nos lleve a abandonar cuál es el verdadero fin de una ley integral: valorar aspectos esenciales de la tutela de la víctima, que tienen más que ver con la implementación correcta de protocolos que faciliten los procesos de identificación, de denuncia, de recuperación y de sostenimiento de las víctimas, que con los aspectos punitivos que no cumplen siempre de manera adecuada la prevención para evitar el delito.

Limitarse a la trata con fines de explotación sexual supone, además, desatender el mandato de la Directiva del 2011 y olvidar que la verdadera prevención ha de tomar en consideración todas las formas de explotación y ha de pasar por la pedagogía antes que por la pena.

Por ello, si se opta por su aprobación, se deberían introducir cambios en el sistema penal de tutela (regulación de un tipo abierto en el que puedan encontrar cobijo todos los fines de explotación, revisión de los delitos conexos y sus penas para evitar problemas de proporcionalidad, creación de delito de esclavitud, etc.), pero que atienda, fundamentalmente, a la perspectiva transversal que desde Europa exige, poniendo el foco en las víctimas. Esto es, lo importante de la ley integral es que gestione de manera adecuada el cúmulo de normas que afectan al fenómeno, y que le dote de un ámbito de prevención específico, 
atendiendo a todas las clases de trata y no solo a las que afectan a la explotación sexual de las mujeres.

\section{Bibliografía}

CUENCA GARCÍA, M.J.: "El perfil criminológico del tráfico para explotación sexual en España: un fenómeno viejo con características nuevas", en García Aran, M., (Coord.), Trata de personas y explotación sexual, Granada, 2006.

CUGAT MAURI, M.: "La trata de seres humanos", en Quintero Olivares, G. (Dir), La Reforma penal de 2010. Análisis y comentarios, Pamplona, 2010.

ESQUINAS VALVERDE, P.: "El delito de matrimonio forzado (art. 172 bis CP) y sus relaciones concursales con otros tipos delictivos, en RECPC, 20-32 (2018).

GARCÍA ARÁN, M.: "Introducción”, en García Arán, M (Coord.): Trata de personas y explotación sexual, Granada, 2006.

GARCÍA ARÁN, M.: "Los tipos penales acogedores del tráfico de personas", en García Arán, M (Coord.): Trata de personas y explotación sexual, Granada, 2006.

GARCÍA ESPAÑA, E. y Rodríguez Candela, J.L.:"Delitos contra los derechos de los extranjeros (art. 318 bis del Código penal)" en Actualidad penal, n 29, julio-2002.

IGLESIAS SKULJ, A.: "De la trata de seres humanos: artículo 177 bis CP", en González Cussac, J.L. (Director), Comentarios a la Reforma del Código penal de 2015, $2^{\mathrm{a}}$ edición, Valencia, 2015.

LEÓN VILLALBA, F.J. (de): Tráfico de personas e inmigración ilegal, Valencia, 2003.

LLORIA GARCÍA, P.: “Apuntes sobre la evolución normativa internacional en materia de trata de personas con fines de explotación sexual", en Serra Cristóbal, R. (Coord.): Prostitución y trata. Marco jurídico y régimen de derechos, Valencia, 2007. 
MAQUEDA ABREU, M.L.: “A propósito de la trata y de las razones que llevan a confundir a 1@s inmigrantes con esclav@s”, en Carbonell Mateu, J.C., González Cussac, J.L. y Orts Berenguer, E., (Dir.) y Cuerda Arnau, M.L. (Coord.), Constitución, Derechos fundamentales y sistema penal (semblanzas y estudios con motivo del setenta aniversario del profesor Tomás Salvador Vives Antón), Tomo II, Valencia, 2009.

MAQUEDA ABREU, M.L.: "Demasiados artificios en el discurso jurídico sobre la trata de seres humanos" en Liber Amicorum en homenaje del Profesor Juan Terradillos Basoco, Valencia, Tirant lo Blanch, 2018.

MAQUEDA ABREU, M.L.: "Trata y esclavitud no son lo mismo, pero ¿qué son?" en Estudios jurídicos penales y criminológicos en homenaje al Prof. Dr. Dr. H.C. mult. Lorenzo Morillas Cueva, Dykinson, 2018.

PÉREZ CEPEDA, A.I.: Globalización, tráfico internacional ilícito de personas y derecho penal, Granada, 2004.

PÉREZ CEPEDA, A.I.: "Las normas penales españolas: cuestiones generales" en García Arán, M. (Coord.).: Trata de personas y explotación sexual, Granada, 2006.

PÉREZ FERRER, F.: "Sobre el delito de trata de seres humanos en el Código penal español tras la LO 1/2015, de 30 de marzo", en Estudios jurídicos penales y criminológicos en homenaje al Prof. Dr. Dr. H.C. múlt. Lorenzo Morillas Cueva, Dykinson, 2018.

POMARES CINTAS, E.: "El delito de trata de seres humanos con finalidad de explotación laboral", en EPC, 13-15, 2011.

RODRÍGUEZ MESA, M.J.: Delitos contra los derechos de los extranjeros, Valencia, 2001.

SERRA CRISTÓBAL, R. y Lloria García, P.: La trata sexual de mujeres. De la represión del delito a la tutela de la víctima, Madrid, 2007.

SERRA CRISTÓBAL, R.: "La trata de mujeres como una de las formas más atroces de violencia contra la mujer”, en 
Martín Sánchez, M. (Dir.): Estudio integral de la violencia de género, Valencia, 2018.

SERRANO PIEDECASAS, J.R.: "Los delitos contra los derechos de los ciudadanos extranjeros" en Laurenzo Copello, P. (coord.), Inmigración y derecho penal. Bases para un debate, Valencia, 2002.

TERRADILLOS BASOCO, J.: "Trata de seres humanos", en Álvarez García, J. y González Cussac, J.L., Comentarios a la Reforma penal de 2010, Valencia, 2010.

VILLACAMPA ESTIARTE, C.: "El delito de trata de seres humanos" en Gonzalo Quintero (Dir.): Comentario a la Reforma penal de 2015, Pamplona, 2015.

VILLACAMPA ESTIARTE, C. y Torres Rosell, N.: "Trata de seres humanos para explotación criminal: ausencia de identificación de las víctimas y sus efectos", en $E P C$, Vol. XXXVI (2016). 